\title{
Peak expiratory flow assessment in smokers liabilities
}

\begin{abstract}
Introduction: The world health organization (WHO) recognizes smoking as a chronic and epidemic disease encouraged through personal experiences and/or public advertisements, and is considered to be the single largest preventable cause of illness and early death worldwide. The inhalation of smoke resulting from the burning of derivatives of all types of tobacco, by non-smoker, constitutes the so-called secondhand tobacco smoke. It is the third avoidable cause of death in the world, after active smoking and alcoholism.
\end{abstract}

Purpose: To evaluate Peak Expiratory Flow (PEF) in smokers liabilities.

Methods: The sample consisted of 40 participants who were divided into two groups: 20 smokers liabilities (exposed group) and 20 participants not exposed to environmental tobacco smoke (ETS - control group). The Peak Flow Meter Medicate ${ }^{\circledR}$ was used to measure expiratory flow. Student's t-test was used to compare the variables obtained. Data were analyzed using BioEstat ${ }^{\circledR} 5.3$ software.

Results: No statistical differences were observed in the comparison of PEF values between the group exposed and not exposed to ETS $(p=0.82)$. There was no difference among those practicing and not practicing physical activity in the group exposed to ETS $(p=0.29)$ and in the PEF values between the group exposed to ETS with age above and below 25 years $(\mathrm{p}=0.73)$.

Conclusion: there were no significant changes in the PEF in the passive of smokers. Passively smoking does not seem to alter lung function.
Volume I Issue 6 - 2017

\author{
Pedro Henrique Donini,' Telma Lissandra Di \\ Pietro, ${ }^{2}$ Igor Fagioli Bordello Masson, ${ }^{3}$ \\ Mauricio Correa Lima ${ }^{4}$ \\ 'Physiotherapist graduated from Universidade Paulista UNIP, \\ Brazil \\ ${ }^{2}$ Physiotherapist, Master in Pulmonology, UNIFESP, Paulista \\ University UNIP, Brazil \\ ${ }^{3}$ Physiotherapist, PhD in Health Sciences at UNIFESP, \\ Universidade Paulista UNIP, Brazil \\ ${ }^{4}$ Physiotherapist, Master of Science from USP, Universidade \\ Paulista UNIP, Brazil
}

Correspondence: Mauricio Correa Lima, Physiotherapist, Master of Science from USP, Professor of the Physiotherapy course of Universidade Paulista, Brazil, Tel + 55 (II) 99184-3337, Emailmamau54@gmail.com

Received: June 08, 2017 | Published: September 26, 2017

Keywords: smokers liabilities, peak expiratory flow, tobacco, flow meter

\section{Introduction}

The World Health Organization (WHO) recognizes smoking as a chronic and epidemic disease and is considered to be the single largest preventable cause of illness and early death worldwide. Moreover, it accounts for the death of one in ten adults worldwide, which may represent about 5 million deaths each year. ${ }^{1}$ An aggravating factor is the passive inhalation of tobacco smoke by non-smokers. Secondhand smoke is considered to be the third leading cause of preventable death in the world after active smoking and alcoholism. ${ }^{2}$

Environmental tobacco smoke (ETS) is a mixture of gases and particles derived from tobacco smoke in the act of smoking, consisting of smoke that comes from the tip of the cigarette when it is not being inhaled (side or secondary smoke) and also the smoke exhaled by the smoker (exhaled or primary smoke). Furthermore, ETS is a problem in the maintenance of air quality indoors and it is proven that many of its chemical components are toxic and carcinogenic. In addition, their inhalation can cause several health damages ${ }^{3,4}$ such as changes in lung function, which can increase bronchial reactivity, airways obstruction and reduction in spirometric values, as well as reduced peak expiratory flow (PEF). ${ }^{5-7} \mathrm{PEF}$ is a measure of pulmonary function and can be defined as the largest flow obtained in a forced expiration from a complete inspiration at the level of Total Pulmonary Capacity (TPC). ${ }^{5,8,9}$ Several studies have reported that ETS exposure in adults also results in a significant impairment of pulmonary function. ${ }^{10,11}$ Therefore, the aim of this study was to compare PEF in smokers liabilities with participants not exposed to ETS.

\section{Patients and methods}

This is a cross-sectional, observational and non-therapeutic study. It was approved by the Ethics Committee of Universidade Paulista (1.103.449), and performed in participants considered to be smokers liabilities, obtained through personal contact of the authors. We enrolled 20 smokers liabilities and 20 participants not exposed to ETS (control group).

All participants were invited to participate in the research and answered a simple questionnaire, Developed by the authors, with data, exclusion criteria, and a question asked if he practiced physical activity regularly. The inclusion criteria were healthy and nonsmokers participants exposed to ETS by close contact with smokers in their homes, workplace or elsewhere. Individuals with pulmonary and cardiovascular diseases, taking bronchodilator medication, temporomandibular joint dysfunctions, and grippe episodes during the evaluation, were excluded.

The Peak Flow Meter Medicate ${ }^{\circledR}$ (Figure 1) manufactured by Fyne Dynamics Ltd was used to measure PEF. To obtain PEF values the participants were instructed to remain in an orthostatic or seated position with the dorsal region away from the backrest, with the mouthpiece firmly positioned around the mouth to avoid air leaks. After this procedure, participants were encouraged to perform maximal expirations from TPC when commanded by the evaluator, with a 30-second interval between the measurements in order to avoid respiratory muscle fatigue. ${ }^{12}$ It was repeated three times and the highest 
value of the measurements was considered, if the two largest values presented a variation more than $40 \mathrm{~L} / \mathrm{min}$, the participant was asked to perform two additional tests to obtain more coherent measures. ${ }^{13}$

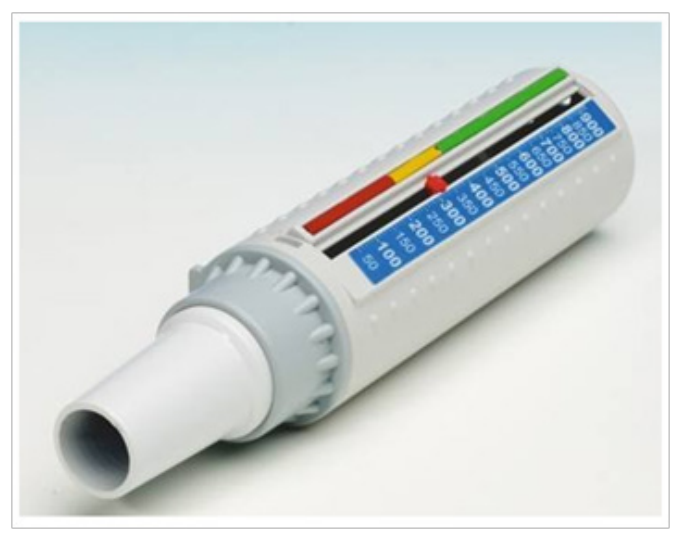

Figure I The peak flow meter medicate $®$ manufactured by fyne dynamics Itd was used to measure PEF.

\section{Statistical analysis}

Descriptive statistics was used to obtain mean and standard deviation of anthropometric variables. Student's t-test was used to verify the homogeneity between groups, and there was no statistical difference between groups. The normal distribution of the variables obtained in the tests was evaluated by Shapiro-Wilk test. Student's t-test for independent samples was used to comparison between and intra groups for PEF. Pvalue $\leq 0.05$ indicates statistical significance. Data were analyzed using BioEstat 5.3 software.

\section{Results}

Forty-one individuals were excluded from the study, because they presented obstructive pulmonary disease. The total sample consisted of 40 participants aged between 18 and 52 years (27.5 \pm 8.7 years). The sample data are described in Table 1 there was no difference between groups ( $p>0.05)$. In the comparison of PEF between smokers liabilities and those not exposed to ETS (control group) there was no statistical difference between groups $(\mathrm{p}=0.82)$ (Figure 2$)$.

Figure $3 \mathrm{~A}$ shows that there was no difference in PEF values between the practitioners and non-practitioners of physical activity in the group exposed to ETS $(\mathrm{p}=0.29)$. Regarding the participants age Figure 3B shows that there was no statistical difference in PEF values between the group exposed to ETS under 25 years and participants over 25 years $(\mathrm{p}=0.73)$.

Table I Demographic characteristics of the sample

\begin{tabular}{lllll}
\hline & \multicolumn{2}{l}{ Group } & & \\
& \multicolumn{1}{l}{ Exposed (N=20) } & & \multicolumn{2}{l}{ Not exposed (N=20) } \\
\cline { 2 - 5 } & Mean & SD & Mean & SD \\
\hline Age (years) & 28.5 & 11.5 & 26.6 & 4.5 \\
Body mass $(\mathrm{kg})$ & 66.6 & 11.6 & 71.1 & 14.6 \\
Height $(\mathrm{m})$ & 1.66 & 0.83 & 1.68 & 0.82 \\
BMI $\left(\mathrm{kg} / \mathrm{m}^{2}\right)$ & 24 & 3.17 & 24.9 & 4.1 \\
Physicalactivity frequency (times/week) & 2.7 & 2.1 & 4.4 & 1.8 \\
\hline
\end{tabular}

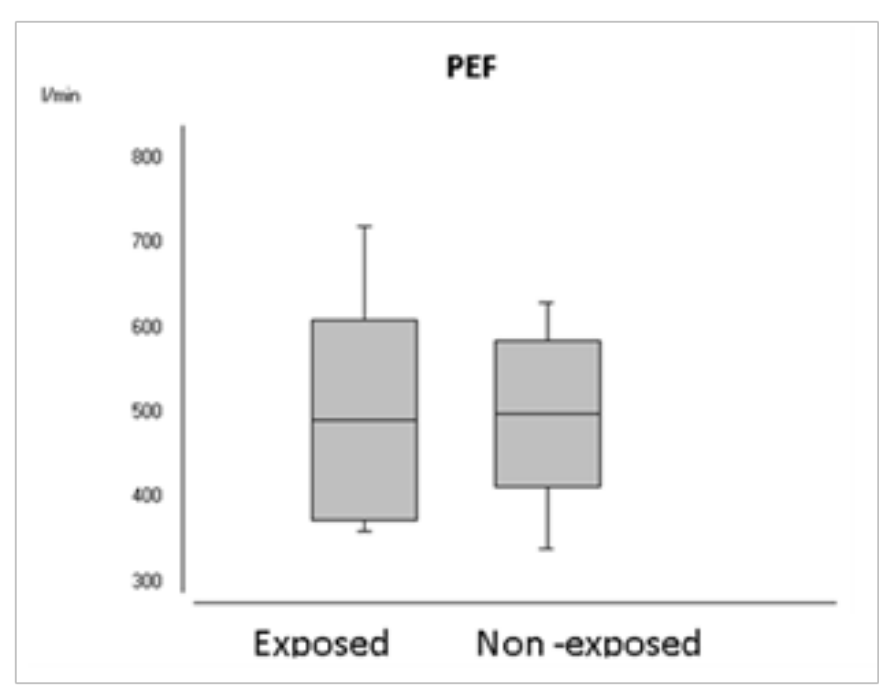

Figure 2 Compared PEF between groups. Student's t-test for independent samples $(p=0.82)$.

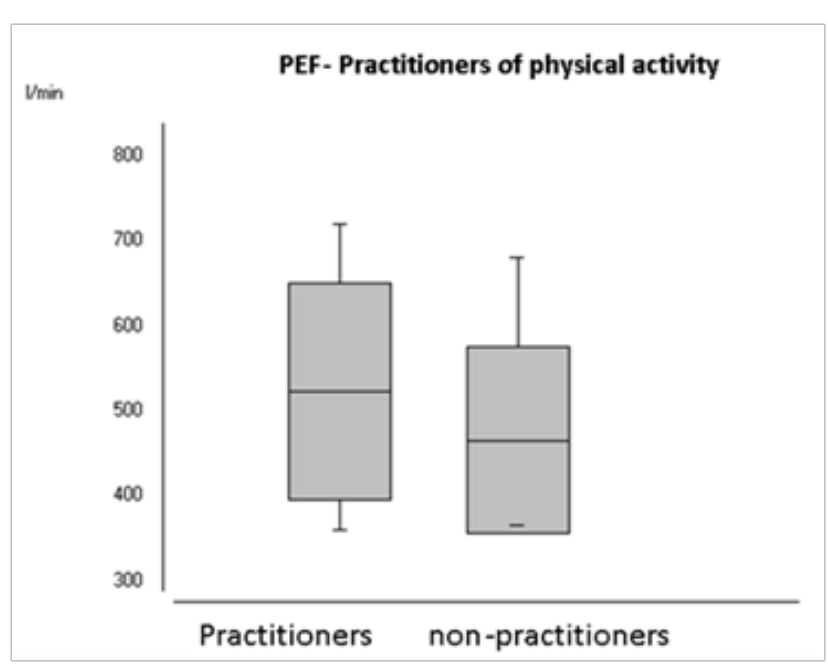

Figure 3A PEF values in practitioners and non-practitioners of physical activity in exposed group to ETS. Student's t-test for independent samples $(p=0.29)$. 


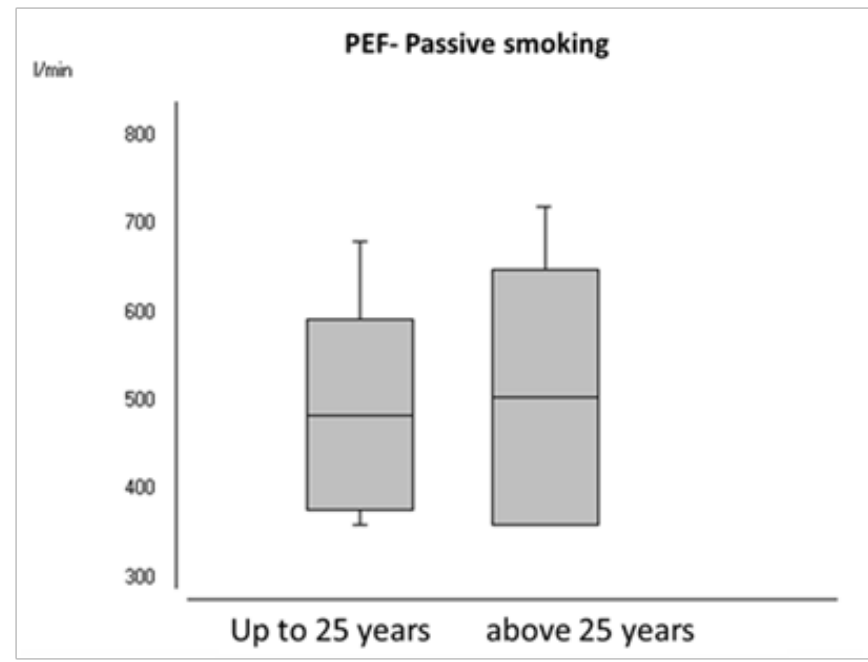

Figure 3B PEF of participants exposed to ETS for age. Student's t-test for independent samples $(p=0.73)$.

\section{Discussion}

The results of our study demonstrated that there were no significant differences in PEF in participants exposed and not exposed to ETS. Currently, smoking is a public health problem and a great hurdle to global development. Though the impact of smoking on health is great in our population, Brazil has demonstrated effective results against smoking. In a comparative study conducted by the World Health Organization (WHO) in 2012, involving countries like China, Russia, Thailand, Bangladesh, Egypt, India, Mexico, The Philippines, Poland, Turkey, Ukraine, Vietnam, among others, Brazil presented the lowest prevalence of tobacco consumption. Moreover, it may be a reflection of several policies the country has been adopting in recent years, such as higher taxation on tobacco products, prohibited smoking in public places, investments in advertising campaigns that warn the population about the consequences of smoking, prohibition of tobacco advertising, sponsorship and promotion of tobacco item. ${ }^{14-15}$ Cao et al. ${ }^{16}$ showed, based on 16 systematic reviews involving 450 original observational studies, that smokers liabilities can significantly increase the risk of cervical, lung, breast and bladder cancer, also raising the risk of certain diseases during childhood, such as asthma.

The inhalation of tobacco smoke, both actively and passively, causes several alterations in the respiratory system, such as increased bronchial thickness, increased mucus production and reduced mucociliary transport, resulting in a narrowing of the airways of smaller calibres, thus reducing airflow with consequent reduction in PEF. ${ }^{1-19}$ Silva et al. ${ }^{20}$ studied the reliability of the PEF meter on the expiratory peak in female smokers and non-smokers, and observed that the female smokers had the lowest PEF compared to non-smokers, concluding that the equipment can be a reliable method to be used in this population. However, the present study did not show differences in PEF in smokers liabilities compared to participants not exposed to ETS, corroborating with our findings that did not show any statistical difference between the groups evaluated.

The aging process is associated with several physiological changes, one of which is the decrease in respiratory muscle strength. ${ }^{21}$ Such reduction is often combined with sedentary lifestyle, and lack of physical activity may accelerate its decline, with lower PEF values expected for this population. ${ }^{22}$ In this study, there was no statistical difference between the PEF values among participants exposed to ETS with less than 25 years of age and also to those who did not practice physical activity.

Regarding the application of questionnaires, Jaakkola et al. ${ }^{23}$ mentioned the advantages of using them as a method of identifying exposure to ETS, describing questionnaire as being relatively inexpensive and can be elaborated in a variety of ways like surveys, e-mails, surveys by phone or in person, and capable to evaluate current and past exhibitions. On the other hand, the US Department of Health and Human Services ${ }^{24}$ affirms the disadvantages of using questionnaires, including classification errors that may result from the interviewer's lack of knowledge about the subject current or past exposure, the difficulty in characterizing exposure in complex internal settings, and recall intentionally or unintentionally.

The degree of exposure to ETS depends on several factors such as the amount of cigarettes the active smoker consumes, number of smokers in the room, size and ventilation of the environment. Although indoor ventilation is a determinant condition in the degree of exposure Seelig et al. ${ }^{25}$ evaluated the influence of ventilation in indoor air quality vulnerable to ETS, arguing that even environments with high ventilation rates do not solve the problem imposed by the ETS.

The results of our study demonstrated that there were no differences in PEF in participants exposed and not exposed to ETS. These results, although in accordance with current literature, may be due to the limited number of individuals evaluated, obtained by convenience sample. The use of a questionnaire as a way of identifying the subjects' exposure to ETS and not obtaining information about their physical activity level may indicate possible limitations in interpreting the results of our study. ${ }^{26-28}$

\section{Conclusion}

There were no changes in the PEF in smokers liabilities when compared to participants not exposed to cigarette smoke. Passively smoking does not seem to alter lung function. However, a better stratification of the sample and evaluation by more specific clinical exams are necessary to obtain a definitive answer on this question.

\section{Acknowledgements}

None.

\section{Conflict of interest}

The authors declares no conflict of interest.

\section{References}

1. Meirelles RHS. Tabagismo e DPOC: dependência e doença - fato consumado. Pulmão RJ - Atualizações Temáticas. 2009;1(1):13-19.

2. Mirra AP, Meireles RHS, Godoy I, et al. Associação medica brasileira e agência nacional de saúde suplementar. Diretrizes Clínicas na Saúde Suplementar. Tabagismo, Brazil; 2009.

3. Nazaroff W, Kleipes N. Environmental tobacco smoke particles. In: Morawska L \& Salthammer T Ed, Indoor environment. airborne particles and settled dust. Hoboken: Wiley, Springer; 2004:245-274.

4. World health organization. Air quality guidelines for Europe. Copenhagen: Denmark; 2007. 
5. Schnabel E, Chen $\mathrm{C}$, Koch B, et al. Regional diferences in prediction models of lung function in Germany. Respir Res. 2010;11(40):1-11.

6. Ohar JA, Sadeghnejad A, Meyers DA, et al. Do symptoms Predict COPD in Smokers? Chest. 2010;137(6):1345-1353.

7. Ulrik CS, Lokke A, Dahl R, et al. Early detection of COPD in general practice. International Int J Chron Obstruct Pulmon Dis. 2011;6:123127.

8. Paes CD, Pessoa BV, Jamami M, et al. Comparação de valores de PFE em uma amostra da população da cidade de São Carlos, São Paulo. $J$ Bras Pneum. 2009;35(2):151-156.

9. Britto RR, Brant TCS, Parreira VF. Avaliação do Pico de Fluxo Expiratório, In: Recursos manuais e instrumentais em fisioterapia respiratória. São Paulo: Manole; 2009. p. 33-45.

10. Xu X, Li B. Exposure-response relationship between passive smoking and adult pulmonary function. Am J Respir Crit Care Med. 1995;151(1):4146.

11. Carrey IM, Cook DG, Strachan DP. The effect of environmental tobacco smoke exposure on lung function in a longitudinal study of British adults. Epidemiology. 1999;10(3):319-326.

12. Tanaka GN, Ruas G, Pessoa BV, et al. Comparison of five portable peak flow meters. Clinics. 2010;65(5):496-474.

13. Quanjer PH, Lebowitz MD, Gregg I, et al. Peak expiratory flow: conclusions and recommendations of a Working Party of the European Respiratory Society. Eur Respir J. 1997;(Suppl 24):2S-8S.

14. Giovino GA, Mirza SA, Samet JM, et al. The GATS collaborative group. Tobacco use in 3 billion individuals from 16 countries: ananalysis of nationally representative cross-sectional household surveys. Lancet. 2012;380(9842):668-679.

15. World Health Organization. Global status report on non communicable diseases 2010. Geneva: Switzerland; 2011.

16. Cao S, Yang C, Gan Y, et al. The health effectsof passive smoking: An overview of systematic reviews based on observational epidemiological evidence. PLoS One. 2015;10(10):1371.
17. Tamashiro E, Cohen NA, Palmer JN, et al. Efeitos do cigarro sobre o epitélio respiratório e sua participação na rinossinusite crônica. Braz J Otorhinolaryngo. 2009;175(6):903-907.

18. Oliveira MVC, Sales MPU. Tabagismo passivo. In: Viegas CAA, editor. Diretrizes para cessação do tabagismo. J Bras Pneumol. 2004.

19. McCoy EK, Thomas JL, Sowell RS, et al. Na evaluation of peak expiratory flow monitoring: A Comparison of sitting versus standing measurements. J Am Board Fam Med. 2010;23(2):166-170.

20. Silva JA, Fonseca MR, Melo MAV, et al. O peak flow expiratório em mulheres fumantes e não fumantes e suas medidas de confiabilidade. Assobrafir Ciência. 2015;6(1):41-48.

21. Ruivo S, Viana P, Martins C, et al. Efeito do envelhecimento cronológico na função pulmonar. Comparação da função respiratória entre adultos e idosos saudáveis. Rev Port Pneumol. 2009;15(4):629-653.

22. Beardsmore CS, Wimpress SP, Thomson AH, et al. Maximum voluntary cough: an indication of air way function. Bull Eur fisiopatol Respir. 1987;23(5):465-472.

23. Jaakkola MS, Jaakkola JJ. Assessment of exposure to environmental tobacco smoke. Eur Respir J. 1997;10(10):2384-2397.

24. US Department of health and human services the health consequences of involuntary smoking. A report of the surgeon general. public health service, Centers for disease control, Center for health promotion and education, USA: 1986.

25. Seelig MF, Campos CRJ, Carvalho JC. A ventilação e a fumaça ambiental de cigarros: um estudo sobre a qualidade do ar de ambientes fechados sujeitos à FAC. Rev da Amrigs. 2005;49(4):253-256.

26. Freitas FS, Parreira VF, Ibiapina CC. Aplicação clínica do pico de fluxo da tosse: uma revisão de literatura. Fisioter Mov. 2010;23(3):495-502.

27. Smith JA, Aliverti A, Quaranta M, et al. Chest wall dynamics during voluntary and induced cough in healthy volunteers. $J$ Physiol. 2012;590(3):563-574.

28. Ishida $\mathrm{H}$, Kobara $\mathrm{K}$, Osaka $\mathrm{H}$, et al. Correlation between peak expiratory flow and abdominal muscle thickness. J Phys Ther Sci. 2014;26(11):1791-1793. 